\title{
El Parque Natural Bahía de Cádiz: un espacio litoral singular
}

\author{
Francisco Javier Bravo Rosano \\ Director-Conservador del Parque Natural \\ Bahia de Cádiz
}

Cuando en el año 1989 se incluyó a la Bahía de Cádiz en el Inventario de Espacios Naturales Protegidos de Andalucía con la categoría de Parque Natural ', se hizo una fuerte apuesta por frenar el proceso de deterioro ambiental que venía sufriendo la zona. Un año antes, en el verano de 1988, se había aprobado la Ley de Costas lo que permitía empezar a ver con cierto optimismo el futuro de las marismas, salinas y playas que habían resistido al proceso de desecación y urbanización desatado en la década de los setenta. Nace de esta forma un Parque Natural bastante singular. A la diversidad de ecosistemas que engloba (marismas mareales, salinas, pinares y playas) con gran variedad de invertebrados, aves y peces, se une el hecho de estar rodeado por cinco importantes núcleos urbanos (Cádiz, San Fernando, Chiclana de la Frontera, Puerto Real y El Puerto de Santa María) que albergan a más de 400.000 personas, cifra que en la temporada estival se ve considerablemente aumentada. No en vano, la Bahía de Cádiz es en la actualidad la tercera aglomeración urbana de Andalucía atendiendo al tamaño de su población. Estos cinco núcleos se encuentran rodeados por marismas mareales, la mayor parte de ellas transformadas desde antaño en salinas, que actualmente conforman el Parque Natural. Pero hasta llegar a gozar del grado de protección que actualmente ostentan, estas zonas húmedas han sufrido en las últimas décadas un importante proceso de deterioro y degradación derivado fundamentalmente de su carácter periurbano.

La crisis de la actividad salinera a lo largo del siglo $X X$ y el consiguiente abandono de las labores de extracción de la sal en las marismas transformadas propició que estos terrenos pasaran a ser considerados improductivos y como consecuencia se originó un proceso de desecación y relleno de la lámina de agua con la finalidad de albergar otros usos. En algunos casos, los rellenos servían para el propio crecimiento urbanístico de los municipios, para la instalación de polígonos industriales o para ubicar en ellos vertederos de residuos sólidos urbanos, todo ello propiciado por el planeamiento urbanístico de los municipios del ámbito. En la mayoría de los casos, estas actuaciones de destrucción de las zonas inundables eran promovidas por las propias administra-
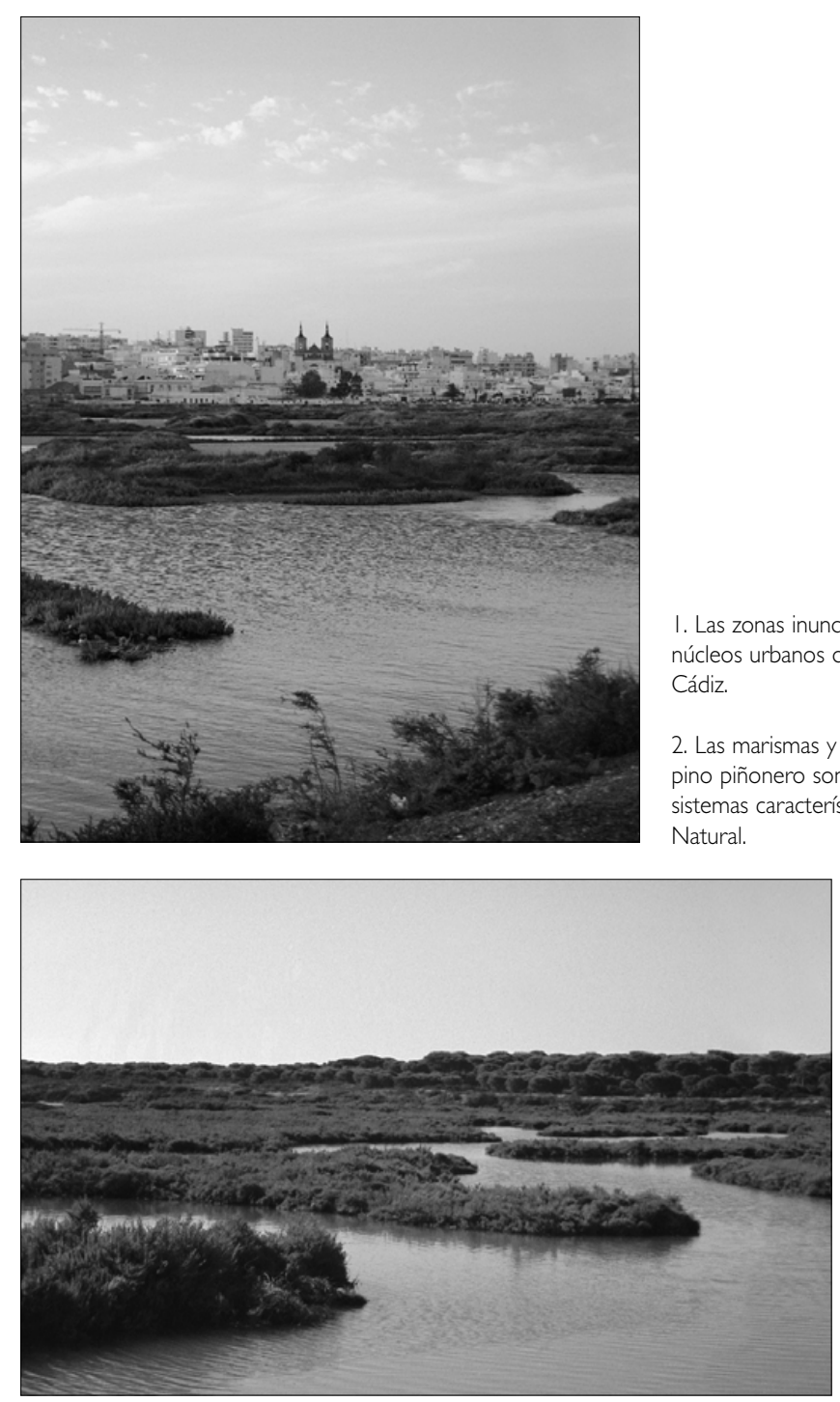

ciones. Especialmente llamativo resulta el caso de la desecación de más de 4.000 hectáreas de marismas en los años sesenta y setenta para su puesta en regadío promovida por el Instituto Nacional de Colonización. Veinte años después se constata que el 90\% de las marismas que fueron desecadas no son aptas para el riego por su alto grado de salinización.

En este contexto nada favorable para la conservación del patrimonio natural de la Bahía de Cádiz, a principios de la década de los ochenta comienzan a alzarse las primeras voces demandando un tratamiento distinto para estas zonas húmedas y para la riqueza ecológica que albergan. Entre ellos destacan los estudios coordinados por Florencio Zoido Naranjo 2 y por Francis Fourneau y Eric Guillemot ${ }^{3}$ así como la propuesta de Parque Natural y Reservas Integrales de la
I. Ley $2 / 1989$, de 18 de junio, por la que se aprueba el Inventario de Espacios Naturales Protegidos de Andalucía y se establecen medidas adicionales

2. ZOIDO NARANJO, Florencio. Bahía de Cádiz: Bases para la Coordinación del Planeamiento Urbanístico. Diputación Provincial. Cádiz, 1982

3. FOURNEAU, Francis y GUILLEMOT, Eric. Evolución del Paisaje y Ordenación del Territorio en Andalucía Occidental. Bahía de Cádiz. Diputación Provincial. Cádiz, 1986 para su protección. 


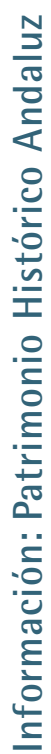

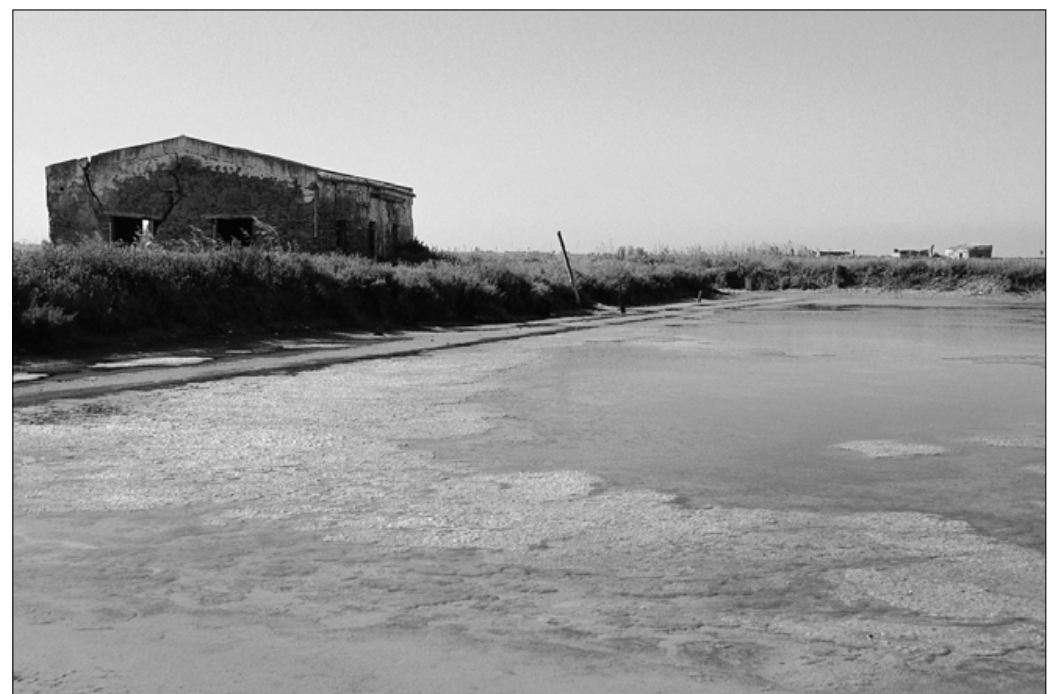

3. Las viejas edificaciones salineras forman parte del paisaje característico de la Bahía de Cádiz.

4. La propuesta fue realizada por los colectivos ecologistas ARAUCARIA, de Cádiz, GUADALETE, de El Puerto de Santa María, y ORTIGA, de San Fernando.

5. SUAREZ JAPÓN, Juan Manuel. La casa salinera de la Bahía de Cádiz. C.O.P.T.Diputación Provincial. 1989

6. Decreto $99 / 1994$, de 3 de mayo, por el que se aprueba el Plan de Ordenación de los Recursos Naturales y el Plan Rector de Uso y Gestión del Parque Natural Bahía de Cádiz.
Bahía de Cádiz elaborada por los colectivos ecologistas de la zona ${ }^{4}$. Como punto en común de estos estudios destaca la apuesta por mantener el esquema polinuclear del sistema urbano de la Bahía de Cádiz, desechando la idea de una gran conurbación que había llegado a ser planteada, y conservar como espacios libres sometidos a algún régimen de protección las marismas, salinas, playas y pinares litorales que conforman el espacio periurbano.

La plasmación normativa de esta nueva visión de las zonas húmedas de la Bahía de Cádiz encaminada a la regulación de usos y a la implantación de un régimen de protección vino de la mano de los instrumentos previstos por la legislación urbanística. En el año 1.986 se aprueba el Plan Especial de Protección del Medio Físico de la Provincia de Cádiz promovido por la Consejería de Política Territorial de la Junta de Andalucía. Este Plan Especial, y su correspondiente Catálogo, supuso la identificación e inventario de las zonas naturales más relevantes sirviendo de base

para la declaración de la mayor parte de los espacios naturales actualmente protegidos en la provincia. El Catálogo del Plan Especial incluyó diversas zonas de la Bahía de Cádiz sometiéndolas bien a un régimen de protección compatible (Marismas de Los Toruños y Playa de Levante, Salinas del Arillo y Sancti Petri, Salinas de los Ríos San Pedro y Guadalete, Pinar del Río San Pedro) o a un régimen de protección integral (Marismas y Salinas del Trocadero), lo que supuso que el Planeamiento Urbanístico de los municipios considerara estas zonas como Suelo No Urbanizable Protegido e incorporara en su normativa las limitaciones de uso encaminadas a garantizar dicha protección.

Sobre la base de los espacios incluidos en el Catálogo del Plan Especial de Protección del Medio Físico de la Provincia de Cádiz en el ámbito de la Bahía, se declara en el año 1.989 el Parque Natural Bahía de Cádiz incluyendo las marismas mareales (transfor- madas o no), las playas que habían resistido al proceso urbanizador y los pinares costeros, con una superficie total de 10.000 hectáreas.

Esta zona juega un importante papel ecológico al constituir uno de los principales lugares de cría y alevinaje de peces, crustáceos y moluscos así como hábitat de reproducción, invernada y migración de poblaciones de más de doscientas especies de aves acuáticas llegando a superar la cifra de 65.000 individuos en invernada. Esta riqueza de avifauna motivó la declaración de la Bahía de Cádiz como Zona de Especial Protección para las Aves (ZEPA) al amparo de lo establecido por la Directiva 79/409/CEE estando actualmente en tramitación su inclusión en el ámbito del Convenio Ramsar para la protección de humedales de importancia internacional.

Pero no solo los valores naturales caracterizan a este espacio. La actividad salinera, en gran medida creadora de este paisaje, ha dejado unos restos de gran interés cultural y etnológico como son las casas salineras o los molinos de marea. Es difícil pensar en el paisaje de la Bahía de Cádiz sin estos elementos reflejo de lo que fue la "cultura de la sal" en la zona 5 .

En el momento actual, la regulación de los usos posibles en las distintas zonas del Parque Natural está establecida por el Plan de Ordenación de los Recursos Naturales y el Plan Rector de Uso y Gestión, documentos que fueron aprobados en el año 1994 por Decreto del Consejo de Gobierno de la Junta de Andalucía ${ }^{6}$. En ellos se establece la zonificación de este espacio natural y se dictan las normas básicas de protección y de gestión del mismo.

Transcurrida más de una década desde la declaración del Parque Natural, es posible hacer una somera valoración de lo que ha supuesto el régimen de protección y de ordenación de los usos sobre el territorio y las principales carencias que se detectan. En este sentido, se hace preciso sentar las bases del uso público del Parque Natural. La culminación del proyecto de Red de Senderos de Uso Público de la Bahía de Cádiz permitirá acceder y conocer la riqueza natural y cultural que este espacio alberga. Igualmente se encuentra en marcha el proyecto de Centro de Visitantes del Parque Natural, equipamiento emblemático de estos espacios que permite una primera aproximación al conocimiento de los valores y recursos de la zona.

Por último, destacar que el presente año 2.00 I será clave para el futuro del Parque Natural Bahía de Cádiz. Sobre la base de la experiencia acumulada en los años anteriores, se va a abordar la revisión del Plan de Ordenación de los Recursos Naturales, documento básico para la gestión y ordenación de los usos en el futuro inmediato de este privilegiado y singular espacio. 